\title{
Brief Discussion on Response to Risks of Transnational Investment
}

\author{
Weian Zhu \\ Eli Broad College of Business, Michigan State University, Ann Arbor, 48823, United States of America
}

Keywords: transnational corporations; transnational investment; risk

\begin{abstract}
The investment industry is generally faced with risks, and the risks faced by transnational investment are far greater than the risks faced by domestic investment. Therefore, in the process of transnational investment, it is necessary to first consider how to control investment risk and how to minimize the risk coefficient. This paper makes a detailed analysis on how to deal with the risk of transnational investment from the perspectives of policy, law and culture through the data of the multinational investment companies collected at present and the case of Huawei company, and puts forward some constructive suggestions for the transnational investment of transnational corporations in the future to help transnational corporations avoid risks.
\end{abstract}

\section{Introduction}

Transnational investment is a kind of economic activity which takes multinational corporations as the main body and achieves the profit purpose by owning its assets through the operation of the international market. Because of the late start of transnational investment and lack of certain theoretical knowledge, the investment industry and enterprises should conduct in-depth research, practice, and summarize the experience in time to help the transnational investment of domestic enterprises in the future.

\section{Risk Classification of Transnational Corporations}

\subsection{National Risk.}

The national risk is mainly due to the state sovereignty and the national social change. In the basic sovereignty, the state, as one of the contracts, produces the transnational investment risk directly in the form of unilateral breach of contract and causes the loss of transnational corporations. The policies and regulations of different stages and different periods of the state will follow the development side. Changes in the causes of migration and other factors also indirectly lead to investment risks and indirectly make property losses of transnational corporations. In a reasonable range of risks, the state does not necessarily play the role of the leading and participants, but the change in national policies and regulations is indeed a real impact on the success or failure of transnational investment.

\subsection{Foreign Exchange Risk.}

Changes in the foreign exchange market always make many senior investment analysts unprepared. Changes in the foreign exchange market lead to changes in the value of the exchange rate, which also causes appreciation or depreciation of foreign currency (invisible assets).

\subsection{Operation Risk.}

From the point of view of accounting knowledge, business risk is a kind of unstable financial loss. According to its formation factors and achievements, business risks can be classified into two categories: pure risk and speculative risk. The two risks are essentially different, but they result in totally different results. Pure risk will be lost or lossless. Fundamentally speaking, this risk is not profitable. Speculative risk is the three results of losing, earning and leveling. The best is profit, of 
course, which is totally unavailable for pure risk.

\section{Case Analysis}

\subsection{History of Huawei.}

Huawei was established in 1987, mainly involved in transmission, exchange, wireless, data communication products. In 1999, Huawei formally established the research target of commercial PBX, its main service object is small companies and hotels. In the late 90s, Huawei attempted to expand overseas and set up a joint venture with Beto Huawei in Russia in 1997. Two years later, Huawei also made some breakthroughs in overseas projects, winning projects in Yemen and Laos. After entering the new century, Huawei has accelerated the expansion of foreign markets, greatly promoted investment, and established branches abroad, gradually moving the focus of development to the overseas. After two years, investment in the telecommunications industry was uneconomical, but Huawei's overseas sales have achieved great results, a significant increase of $68 \%$ compared to the previous year.

With the continuous expansion of overseas markets, in 2005, Huawei made a major strategic decision and decided to extend its focus from developing countries to developed countries. In 2008, Huawei was selected as one of the ten most influential companies in the world. At present, Huawei has become one of the largest multinational companies in the domestic market and international market.

Table 1 Profit data

\begin{tabular}{|c|c|c|c|}
\hline RMB(Million Yuan) & 2017 & 2016 & $\begin{array}{c}\text { Year-on-year } \\
\text { change }\end{array}$ \\
\hline Sales income & 603,621 & 521,574 & $15.7 \%$ \\
\hline Gross profit on sales & 238,142 & 210,129 & $13.3 \%$ \\
\hline -Gross profit margin & $39.5 \%$ & $40.3 \%$ & $-0.8 \%$ \\
\hline Period expense & 181,768 & 162,614 & $11.8 \%$ \\
\hline - Period expense margin & $30.1 \%$ & $31.2 \%$ & $-1.1 \%$ \\
\hline Operating profit & 56,384 & 47,515 & $18.7 \%$ \\
\hline - Operating profit margin & $9.3 \%$ & $9.1 \%$ & $0.2 \%$ \\
\hline Cost of financing & 573 & 3,737 & $-84.7 \%$ \\
\hline Income tax expense & 8,673 & 7,006 & $23.8 \%$ \\
\hline Net profit & 47,455 & 37,052 & $28.1 \%$ \\
\hline
\end{tabular}

\subsection{Risk Analysis of Huawei Investment.}

With the rapid development of Huawei group, a very high international position has been achieved, but this has also caused a blind self-arrogance inside of Huawei, which will cause a certain impact on the strategic decision of Huawei in transnational investment, resulting in errors in investment and causing significant losses to the company. In addition, the failure of investment decisions usually makes the investment not good to adapt to the market, investment cannot be completed according to the expectations of the company and will also bring a very bad impact on the company. Blind investment causes great economic losses to the company.

Compared with the international enterprises in the developed countries, the technology of many multinational enterprises in China still has a certain gap, and still rely on the labor force as the main means of benefit. This is also the fundamental reason why China has many multinational companies, but not many world-class companies. To truly go to the world, we must master the core technology. 
Table 2 Costs data

\begin{tabular}{|c|c|c|c|}
\hline RMB (Million Yuan) & 2016 & 2017 & Year-on-year change \\
\hline R \& D cost & 89,690 & 76,391 & $17.4 \%$ \\
\hline R \& D cost rate & $14.9 \%$ & $14.6 \%$ & $0.3 \%$ \\
\hline $\begin{array}{c}\text { Sales and } \\
\text { management costs }\end{array}$ & 92,681 & 86,442 & $7.2 \%$ \\
\hline $\begin{array}{c}\text { Rate of sales and } \\
\text { management costs }\end{array}$ & $15.4 \%$ & $16.6 \%$ & $-1.2 \%$ \\
\hline $\begin{array}{c}\text { Other income and } \\
\text { expenditure }\end{array}$ & 613 & 219 & $-0.06 \%$ \\
\hline $\begin{array}{c}\text { Rate of other income } \\
\text { and expenditure }\end{array}$ & $-0.1 \%$ & $-0.04 \%$ & $11.8 \%$ \\
\hline $\begin{array}{c}\text { Sum of period } \\
\text { expense }\end{array}$ & 181,768 & 1862,614 & $-1.1 \%$ \\
\hline $\begin{array}{c}\text { Rate of period } \\
\text { expense }\end{array}$ & $30.1 \%$ & $31.2 \%$ & \\
\hline
\end{tabular}

PCT top 10 countries

WHICH COUNTRIES ARE THE BIGGEST USERS OF THE PCT SYSTEM?

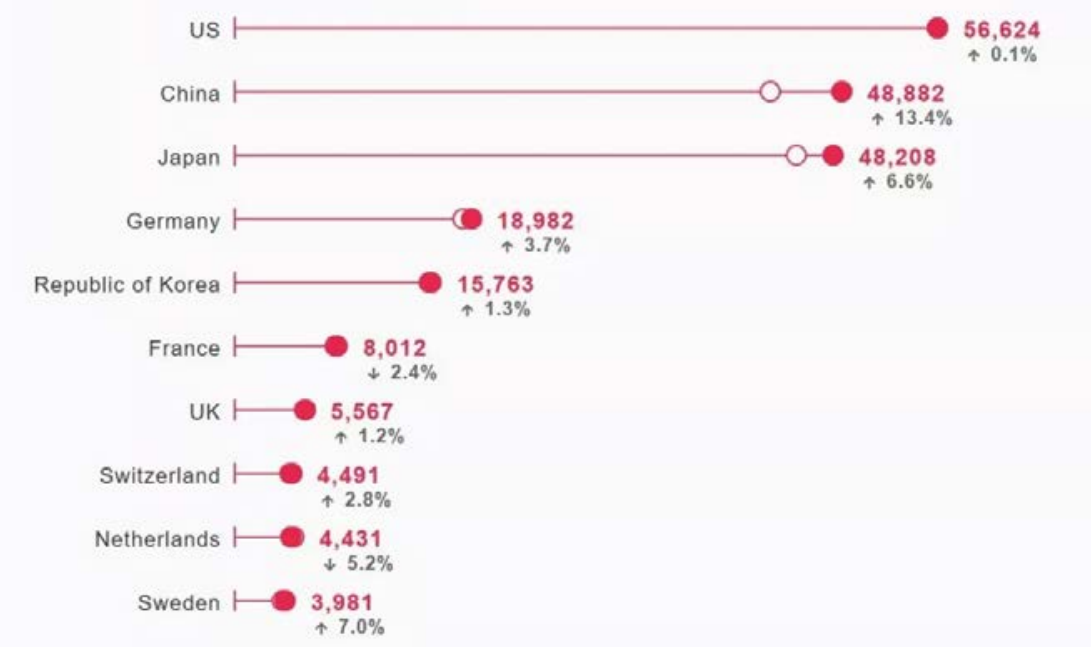

PCT top 10 countries

WHICH COUNTRIES ARE THE BIGGEST USERS OF THE PCT SYSTEM?

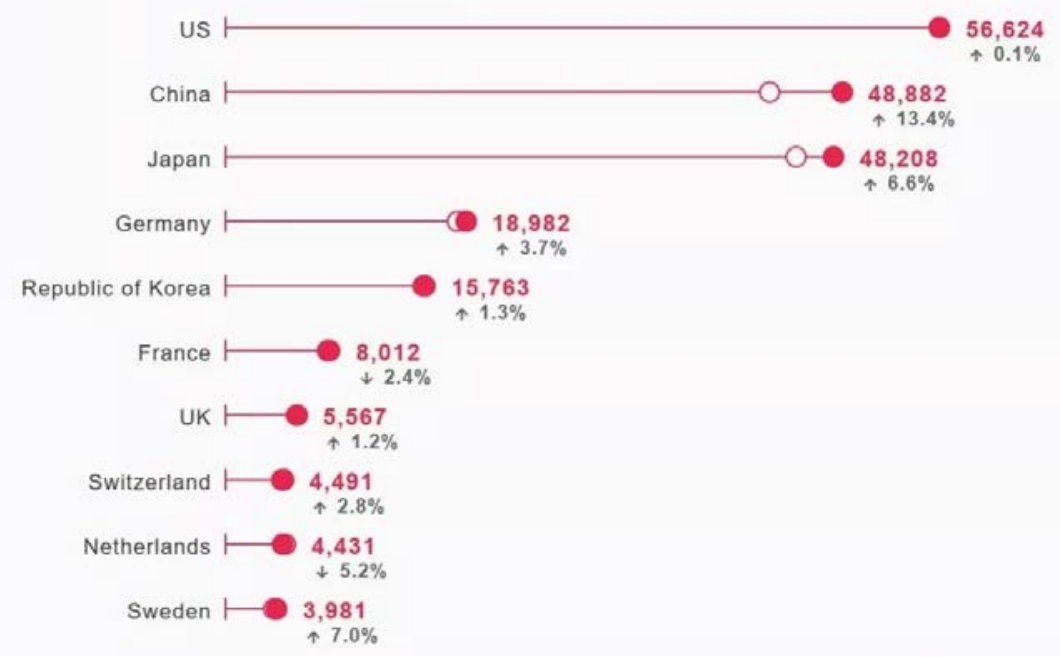

Fig.1 Comparison of the world 
There is still too little experience in the international market in our country. Most of the enterprises are in the exploration stage of the overseas market. The lack of experience leads to the failure of domestic enterprises to control the operation of the international market, which cannot be solved well because of the marketing channels and customer information, which is indirect to the enterprise. The global competition is restricted. Secondly, the lack of experience leads the enterprise to not know the trend of the market in a timely and accurate way. It can't clearly judge when and how to adapt to the market, not to say the forecast for the goods in advance. This makes many enterprises in the dangerous situation of "touching the black woods" when they are expanding overseas. Be careful, otherwise, the enterprise will fall into the abyss.

\subsection{Transnational Investment Analysis of Huawei.}

Political direction. In the period of Russian economic turmoil, many industries in Russia have been loosened. Huawei, as a new multinational company, cooperates with the Russia Company, and the lower price of Huawei has made it fast in Russia. The action of Huawei, which bears great political risk but also to a certain extent, has solved the risk of operation, and has also secured the support of the Russian local government's policy support for better development.

Social risk. In 2008, Huawei began to take in the US market, but failed several times in succession. In 2012, everything changed. Huawei hired former U. S. contractor officials as chief security officer of Huawei in the United States, established a cultural bridge between Huawei and the United States and even between China and the United States, reducing the friction between cultures and eliminating the prejudice of American society and the American government on Chinese enterprises. This also enables more and more foreigners to recognize Huawei through Huawei's technological means and corporate culture. In addition, Huawei employs many local talents as Huawei employees, which has greatly improved the efficiency of the staff. Moreover, most of the leaders of overseas companies, as Chinese people, have only played a major role in policy-making, and have greatly reduced cultural conflicts.

Enterprise risk. Huawei is currently involved in developed and developing countries, and there is no regional and traffic problems. With the rapid development of Huawei, Huawei covers most of the world. In this process, economic difficulties are unavoidable, but because most of the poverty-stricken areas are not too far away from China, it is not necessary to make the funds invested by Huawei. This also reduces the probability of enterprise risk to a certain extent. However, there are some risks in human resources, which will cause potential risks in age structure, educational level, and work experience. This may cause employees to have different performance in the face of welfare, and then affect the sense of belonging of the employees. In recent years, Huawei has been a good incentive mechanism to maintain the enthusiasm of the staff, so that the staff always maintains a high level of work, greatly reduced the turnover rate of enterprises.

Table 3 Benefits data

\begin{tabular}{|l|c|c|}
\hline \multicolumn{1}{|c|}{ RMB (Yuan) } & $\mathbf{2 0 1 7}$ & $\mathbf{2 0 1 6}$ \\
\hline Salary and other benefits & 106,851 & 94,179 \\
\hline Time unit plan & 17,155 & 13,076 \\
\hline \multicolumn{1}{|c|}{ Plan after departure } & & \\
\hline Set income plan & 3,665 & 3,408 \\
\hline Quota provision plan & 12,614 & 11,209 \\
\hline
\end{tabular}

Market risk. Huawei has been involved in many parts of the world, and Huawei has always adhered to the principle of local development. This also enables Huawei to grasp the market in a timely manner and make the right development strategy. In addition, Huawei produces different products according to different regions and takes advantage of low cost to occupy the unsaturated market. This also effectively improves the competitiveness between Huawei and host enterprises, thus evading enterprise risk. 


\section{Summarization of Transnational Investment Suggestions}

Through the analysis of Huawei cases, we can see that transnational investment is not a simple process, it involves a lot of factors, only one or a small number of factors cannot be truly realized. However, due to the defects of most enterprises' knowledge, the risk of transnational investment cannot be controlled. Therefore, some independent risks can be independently analyzed to minimize the risk of transnational investment. Multinational corporations are divided into three main categories: foreign exchange risk, state risk and operational risk. From a macro perspective, they are divided into industry risk and enterprise risk.

\section{Conclusion}

Through a small number of cases involving Huawei enterprises and other enterprises, we can see that the risk of transnational investment must be prevented ahead of schedule. In recent years, Huawei has been developing along this line. It is precisely this reason that Huawei has come to this stage today. At present, the investment industry is generally faced with risks. How to control investment risks has become an urgent problem. This paper makes a detailed analysis of how to deal with the risk of transnational investment from the perspectives of policy, law and culture through the data of the multinational investment companies collected at present and the case of Huawei company, and puts forward some constructive suggestions for the transnational investment of the multinational corporations in the future to help transnational corporations avoid risks.

\section{References}

[1] Liu Junmin,Wang Qian. Reconstructing International Economic Theory from the Viewpoint of Fictitious Economy - New Development of Contemporary International Economic Relationship and Its Enlightenments to China’s Economy [J]. China Industrial Economy, 2005(11): 18-25.

[2] LiMeng, Yu Jinping. The Research on Correlation between Host Country's Location Advantage and China's Outward FDI: A GMM Analysis based on Dynamic Panel Data with IntercrossVariable [J]. World Economy Studies, 2011(6): 63-74.

[3] Zhou Yinmeng, Fu Shihan, Zhuang Pengchong. From 'Theory-driven Paradigm' to 'Problem-driven Paradigm' - The Researching Paradigm Changing of Chinese Firms Global Strategy [J]. Journal of Central University of Finance \& Economics, 2012(12): 76-80.

[4] Xie Mengjun, Guo Yanru. The Effect Of Legal System Quality on China’s Outward Foreign Direct Investment Location Choice: An Empirical Test Based on the Perspective of Investment Motivation [J]. International Economics and Trade Research, 2013, 29(6): 107-118.

[5] Zhongyuan Zhang. Institutional Quality, Bilateral Investment Treaties and China's Outward Foreign Direct Investment: An Empirical Analysis Based on Panel Threshold Regression [J]. South China Journal of Economics, 2013(4): 49-62. 